\title{
Vieussens' Arterial Ring Visualized by MDCT
}

\author{
Mohamed Bamoshmoosh ${ }^{1,2 *}$, Fabio Fanfani' ${ }^{1}$, Cecilia Volpe ${ }^{1}$ \\ ${ }^{1}$ Radiology Department, Fanfani Clinical Research Institute, Florence, Italy \\ ${ }^{2}$ Cardiology Department, University of Science and Technology, Sana'a, Yemen \\ Email: ${ }^{\text {bamoshmoosh@hotmail.it }}$
}

Received 13 May 2013; revised 5 August 2013; accepted 15 August 2013

Copyright (C) 2014 by authors and Scientific Research Publishing Inc.

This work is licensed under the Creative Commons Attribution International License (CC BY). http://creativecommons.org/licenses/by/4.0/

(c) () Open Access

\begin{abstract}
Here we present the case of a patient studied with multi-detector computed tomography (MDCT). Due to a severe three-vessel coronary artery disease he underwent coronary artery by-pass graft surgery. Two years later because of dyspnea and chest pain he was referred to have coronary computed tomography angiogram. We describe the coronary artery findings as well as the presence of a Vieussens' arterial ring, which is not commonly visualized by traditional angiography. In the medical literature Vieussens' arterial ring cases described by MDCT are extremely rare. This case shows how MDCT can be crucial in correctly understanding the anatomy of coronary artery disease patients.
\end{abstract}

\section{Keywords}

Coronary Artery Disease; Vieussens' Arterial Ring; MDCT

\section{Introduction}

The presence of ipsilateral or contralateral coronary circulation is important to characterize patients with coronary artery disease (CAD) and is useful in deciding their management. For this reason during traditional coronary angiography it is necessary to carefully look for the coronary collateral circulation even if this prolongs the radiological exposure of the patient.

Multidetector computed tomography (MDCT) does not explore the coronary collateral circulation dynamically and, due to its limited spatial resolution, is unable to visualize sub-millmetric collaterals.

There are however cases where the coronary collateral circulation had enough time to become a well developed epicardial vessel that can be seen even with MDCT. In these cases the coronary collateral circulation acts as a real arterious by-pass that fills the vessel distal to the occlusion or severe stenosis.

One of these coronary collateral circulations is the Vieussens' arterial ring (VAR). VAR is an infrequent col-

${ }^{*}$ Corresponding author.

How to cite this paper: Bamoshmoosh, M., Fanfani, F. and Volpe, C. (2014) Vieussens' Arterial Ring Visualized by MDCT. Open Journal of Radiology, 4, 9-12. http://dx.doi.org/10.4236/ojrad.2014.41002 
lateral pathway between the conus branches of the right and left coronary arteries. VAR was first described by French anatomist Raymond de Vieussens in 1706 and appeared in the literature in the first edition, in 1858, of Henry Gray's famous textbook of anatomy. VAR is thought to be a remnant of the embryonic cono-truncal circle, that gives rise to the coronary ostia [1]. Pathologic conditions, primarily involving VAR, are very rare and are mainly related to the presence of VAR pseudoaneurysm [2]. Extremely rare are also VAR cases described with MDCT [2]-[4].

\section{Case Report}

The patient of this case report is a 65 years old male in treatment for hypertension and dyslipidaemia. For the presence of effort angina he underwent invasive coronary angiography which showed three-vessel coronary artery disease: occlusion of the left anterior descending coronary artery (LAD) between the proximal and medial segment, severe stenosis of the second diagonal branch (DB), severe stenosis of the first marginal branch (MB) and occlusion of the right coronary artery (RCA) ostium. For this reason he underwent coronary artery bypass graft surgery: left internal mammary artery (LIMA) for the distal LAD, right internal mammary artery for the $\mathrm{MB}$, venous graft for the posterior descending coronary artery (PD) and a venous graft for the DB.

Two years later because of dyspnea and chest pain an anatomical evaluation of the patient's coronary tree was needed and he was referred to have coronary MDCT.

MDCT was performed with 64-slice Brilliance scanner (Philips Healthcare) by administering $100 \mathrm{ml}$ of iodinated contrast medium (Iomeron $400 \mathrm{mg} / \mathrm{dl}$, Bracco Imaging, Italy) followed by $50 \mathrm{ml}$ of saline solution at a rate of $5 \mathrm{ml} / \mathrm{s}$ through 18 gauge cannula placed in the antecubital vein. Images were acquired during a 10 to $15 \mathrm{sec}-$ ond breath-hold with retrospective electrocardiographic gating. After data acquisition on dedicated workstations (Philips Extended Brilliance Workspace; Philips Medical Systems) images were reconstructed especially at the $75 \%$ of the RR interval, with a thickness of $0.6 \mathrm{~mm}$ and increment of $0.3 \mathrm{~mm}$. To reduce patient's heart rate, 30 minutes before the test he was given $100 \mathrm{mg}$ of Metoprolol per os. Coronary computed tomography angiogram provided images which were judged of good quality and showed that LIMA and RIMA grafts were patent as well as the distal LAD and PD (Figure 1). Also the venous graft for the MB was patent with a good visualization of the vessel beneath the distal anastomosis. The venous graft for the DB was however occluded at the origin. Interestingly from the distal LAD, beneath the anastomosis with LIMA there was a well developed coronary collateral circulation (Vieussens' arterial ring) connecting the LAD to the proximal RCA (Figure 1, Figure 2, Figure 3). The results of MDCT advised for the moment to increase the medical treatment of the patient.

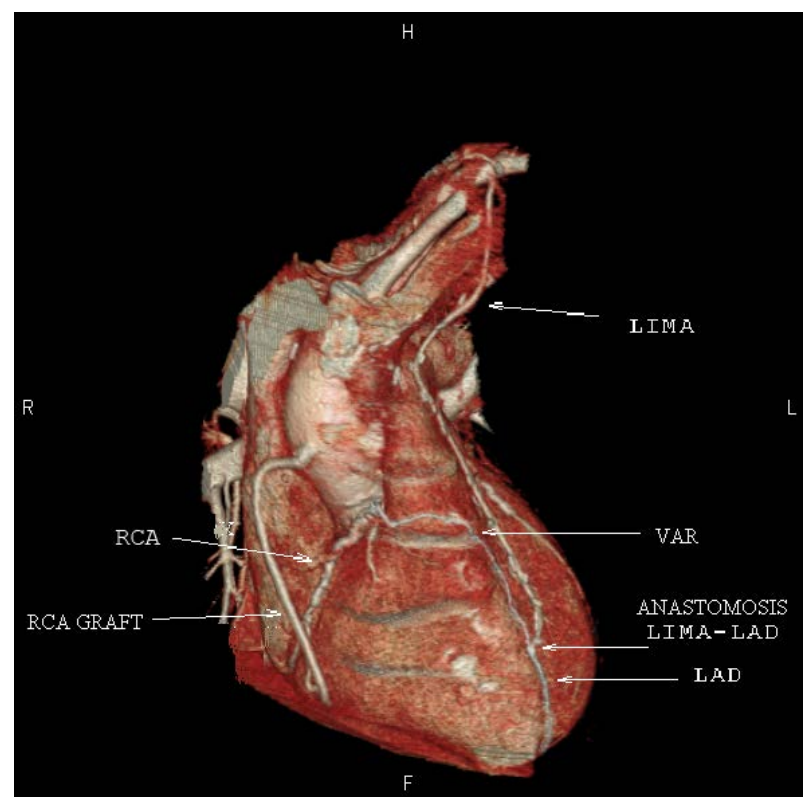

Figure 1. Volume rendering image of the heart. LIMA: left internal mammary artery; LAD: left descending coronary artery; RCA: right coronary artery; VAR: Vieussens’ arterial ring. 


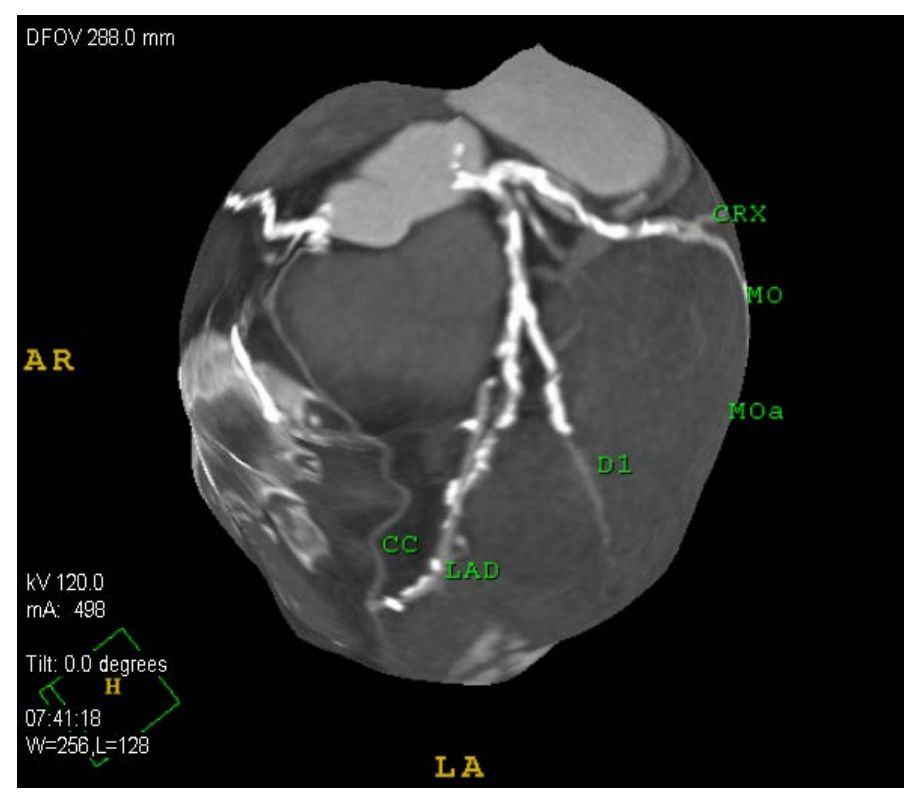

Figure 2. 3 D map of coronary arteries: LAD: left descending coronary artery; D1: first diagonal branch; CRX: circumflex artery; MO, marginal branch; CC: collateral circulation (Vieussens’ arterial ring).

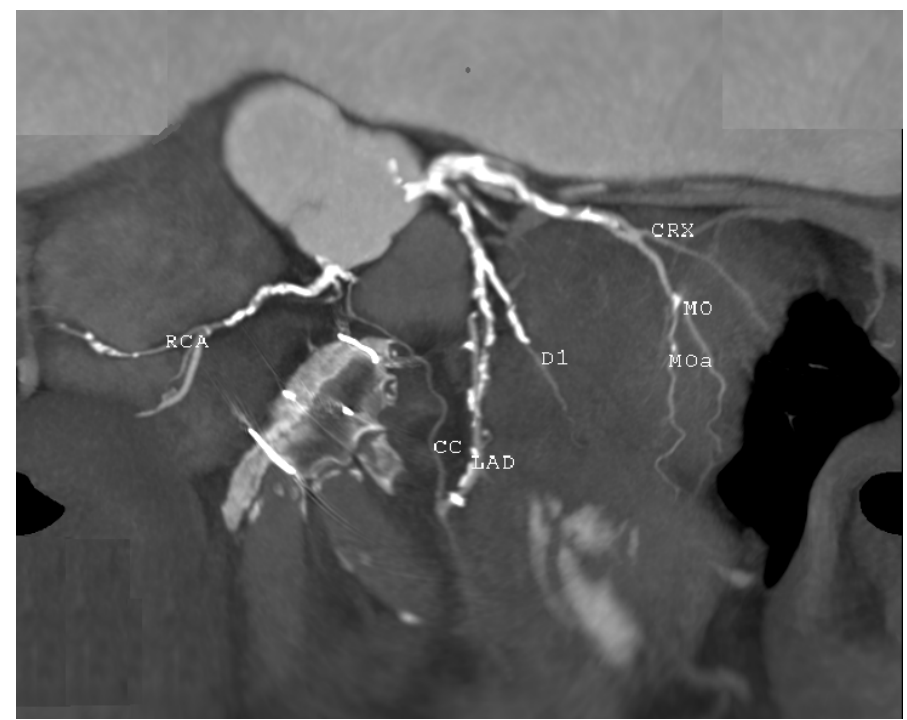

Figure 3. 2 D map of coronary arteries: LAD: left descending coronary artery; D1: first diagonal branch; CRX: circumflex artery; MO, marginal branch; RCA: right coronary artery; CC: collateral circulation (Vieussens' arterial ring).

\section{Discussion}

Invasive coronary angiography is the "gold standard" technique to evaluate coronary arteries and in more than a half-century experience it proved to be extremely reliable in the diagnostical processes of CAD patients. However invasive coronary angiography is not always the most appropriate test with which we can evaluate CAD patients. The introduction in the cardiac arena of MDCT, which investigates coronary arteries with good accuracy, provided us with a complementary test to traditional coronary angiography [5]. In particular settings that can range from quite simple cases (identification of the anomalous origin of a coronary artery) to very complex cases (need to pre-plan a re-do bypass surgery), or that of the patient of this case report it can be considered an alternative technique to invasive coronary angiography [5]. In this case MDCT was able to evaluate the coronary collateral circulation, and was of great help in correctly understanding patient's coronary tree. The information 
obtained with MDCT could be discussed by cardiologists and surgeons before any therapeutical decision and could avoid sudden decisions during invasive procedures and this may lead to a change in the diagnostical and therapeutical process of CAD patients. Some doubts are however present regarding the amount of radiation given with MDCT. In fact the effective radiation dose of 64-MDCT without tube current modulation is $15 \mathrm{mSv}$ (range $12-18 \mathrm{mSv}$ ), which is higher than that of traditional coronary angiography (7 mSv; range 2 - 16) [6]. However recent improvements in MDCT technology reduced the radiation dosage significantly to almost equal or even to be less than that of traditional coronary angiography [7]. However to better understand the real usefulness of MDCT and correctly allocate it in the flow chart of the evaluation of CAD patients more experience must be gained by routine users, and further multi-centric interdisciplinary studies must be performed till the implementation of approved clinical practice guidelines.

\section{Conclusion}

In this paper we describe the case of a patient with severe coronary artery disease already treated with coronary artery by-pass surgery. Because of the presence of dyspnea and chest pain he underwent CT coronary angiography. The results of this examination showed the presence of Vieussens' arterial ring, which is rarely visualized by CT coronary angiography. This case shows how CT coronary angiography can be crucial in correctly understanding the anatomy of coronary artery disease patients.

\section{References}

[1] O’Leary, E.L., Garza, L., Williams, M. and McCall, D. (1998) Images in Cardiovascular Medicine. Vieussens’ Ring. Circulation, 98, 487-488. http://dx.doi.org/10.1161/01.CIR.98.5.487

[2] Owen, A.R., Moten, S.C. and Molan, M.P. (2009) Rupture of an Aneurysm of Ieussens' Arterial Ring Presenting as Acute Cardiac Tamponade. Clinical Radiology, 64, 1129-1131. http://dx.doi.org/10.1016/j.crad.2009.05.011

[3] Chan, C.Y., Lee, P.W., Lam, Y.Y., Chan, W.W., Wong, K.T. and Yu, C.M. (2009) Detection of Large Aneurysm of Vieussens' Arterial Ring after Abnormal Shadow on Chest Radiography. Circulation, 120, 134-136. http://dx.doi.org/10.1161/CIRCULATIONAHA.109.865220

[4] Hansen, M.W. and Merchant, N. (2006) Vieussens’ Ring Combining Computed Tomography Coronary Angiography and Magnetic Resonance Imaging in Assessing Collateral Pathways. Circulation, 114, e545-e546. http://dx.doi.org/10.1161/CIRCULATIONAHA.106.629063

[5] Taylor, A.J., Cerqueira, M., Hodgson, J.M., Mark, D., Min, J., O’Gara, P. and Rubin, G.D. (2010) ACCF/SCCT/ACR/ AHA/ASE/ASNC/NASCI/SCAI/SCMR 2010 Appropriate Use Criteria for Cardiac Computed Tomography. JACC, 56, 1864-1894. http://dx.doi.org/10.1016/j.jacc.2010.07.005

[6] Mark, D.B., Berman, D.S., Budoff, M.J., Carr, J.J., Gerber, T.C., Hecht, H.S., Hlatky, M.A., Hodgson, J.M., Lauer, M.S., Miller, J.M., Morin, R.L., Mukherjee, D., Poon, M., Rubin, G.D. and Schwartz, R.S. (2010) ACCF/ACR/AHA/ NASCI/SAIP/SCAI/SCCT 2010 Expert Consensus Document on Coronary Computed Tomographic Angiography. JACC, 55, 2663-2699.

[7] Herzog, B.A., Wyss, C.A., Husman, L., Gaemperli, O., Valenta, I., Treyer, V., Landmesser, U. and Kaufmann, P.A. (2009) First Head-to-Head Comparison of Effective Radiation Dose from Low-Dose CT with Prospective ECG-Triggering versus Invasive Coronary Angiography. Heart, 95, 1656-1661. http://dx.doi.org/10.1136/hrt.2008.162420 